\title{
Design Strategy of Elastoplastic Dampers for Seismic Protection of Structures
}

\author{
Fengmei PI, Wenjie REN*, Bowen CHEN
}

\begin{abstract}
A new methodology for seismic control design of MDOF structures is put forward.The methodology is developed for shear-type building frames with supplemental system of braces with dampers. Hysteretic dampers are modelled to be elasto-perfectly plastic. The mechanical parameters of the damper, the supplemental system (damper + brace) and the controlled structure are first defined. Next, based on modal analysis method, the controlled MDOF structure is converted to the equivalent SDOF structure, and the distribution of elastic stiffness of damper on the MDOF structure is derived. Then, a procedure is compiled to achieve the elastic stiffness, the yielding drift and the ductility factor of the damper on each story of the MDOF structure. Finally, the procedure is used for seismic control design of three example structures. Time history analyses show that the proposed methodology is feasible.
\end{abstract}

Keywords: damper; model analysis method; seismic control design; shear-type frame

\section{INTRODUCTION}

Many past studies and structural applications have proved that passive energy dissipation is an effective technology for enhancing the seismic performance of a structure by adding extra damping and stiffness to the structures [1-7]. For a wider application of supplemental energy dissipation devices, comprehensive analyses have been proposed, such as the direct displacement-based method [8-10], the energy-based method [11-13], the force-based method [14, 15], the capacity-spectrum method [16, 17], and others [18-20]. Furthermore, some codes also provide design criteria, e.g. UBC, FEMA-273 and ATC-40 [8]. Although having the above achievements, research on seismic control design of structures is still a hot topic, because most of the existing methods require relatively significant computational efforts and are difficult to use in practice.

Toward practical use, Kasai et al. [21] proposed a simplified method to predict the seismic performance of viscoelastical and elastoplastical damped steel moment resisting frames. The method first uses an elastic singledegree-of-freedom (SDOF) structure to replace a multidegree-of-freedom (MDOF) structure, then develops seismic performance curves to perform a spectrum-based response prediction and damper capacity design for the equivalent SDOF strucutre, finally distributes the damper capacity from the SDOF structure to the MDOF structure based on the tuning of the equivalent stiffness. Due to not requiring iterative calculation, Kasai's method consumes less computation time, thus is adopted by Japan Society of Seismic Isolation (JSSI) [22] for design engineers to use. Afterwards, $\mathrm{Pu}$ et al. [23] advance the method for designing slip hysteretic timber structures. However, Kasai's method also has the following disadvantages: (1) it adheres to the Japanese seismic code, so the seismic performance curves cannot be thoroughly extended to another code-consistent structure; (2) it is reasonable for most structures with regularities in elevation, but may lead to an unsatisfied design for the structures with the soft stories in elevation; (3) the final value of the ductility factor may be different from the preset value.

Enlightened by Kasai's method, this paper puts forward a new methodology for seismic control design of MDOF structures. The structure is a shear-type building frame, and the hysteretic damper is modeled to be elastoperfectly plastic. First,the mechanical parameters of the damper, the supplemental system (damper + brace) and the controlled structure are introduced. Secondly, on the basis of modal analysis method, an equivalent SDOF structure is used to replace the controlled MDOF structure, then the distribution of elastic stiffness of damper on the MDOF structure is derived. Thirdly, a procedure is written to achieve the parameters of the damper on each story of the MDOF structure. Finally, the procedure is applied for seismic control design of three example structures, among which one is regular in elevation and others have soft stories in upper or lower stories. Time history analysis method is performed to verify the feasibility of the procedure.

\section{METHODOLOGY FOR SEISMIC CONTROL DESIGN OF STRUCTURES}

\subsection{Basic Structure Description}

This paper addresses a shear-type $n$-DOF building frame, in which the bending deformation is far smaller than the shear deformation and is consequently neglected [23]. Dampers and braces comprise the supplemental system. Usually, the dampers are placed diagonally or horizontally at stories of the structure, see Fig. 1.

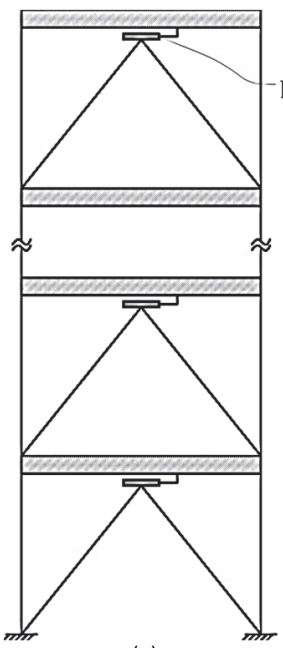

(a)

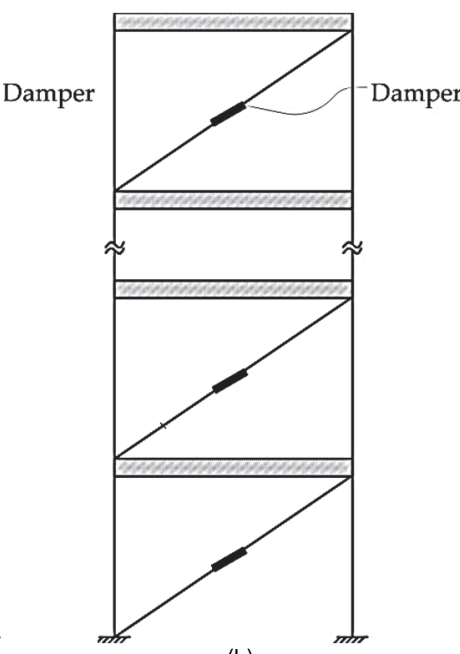

(b)
Figure 1 Sketch of frame with dampers. (a) Chevron configuration; (b) Diagonal configuration 
Research in this paper is based on Fig. 1a. Hysteretic dampers that are based on the yielding of metallic materials are used. Excited by the ground motions, the frame and the brace are assumed to be elastic, and the dampers yield to dissipate vibration energy.

\subsection{Definition of Mechanical Parameters}

Taken the structure in Fig. 1a for example, some mechanical parameters are defined as follows: $k_{\mathrm{f}, i}$ and $k_{\mathrm{b}, i}$ denote the elastic stiffness of the frame and the brace at the $i^{\text {th }}$ story, respectively; $k_{\mathrm{d}, i}, \mu_{\mathrm{d}, i}, \mu_{\mathrm{dy}, i}, \mu_{\mathrm{dmax}, i}$ and $k_{\mathrm{deq}, i}$ denote the elastic stiffness, ductility factor, yielding drift, maximum drift and equivalent secant stiffness of the damper at the $i^{\text {th }}$ story, respectively; $k_{\mathrm{a}, i}, \mu_{\mathrm{a}, i}, \mu_{\mathrm{ay}, i}, \mu_{\mathrm{amax}, i}$ and $k_{\text {aeq, } i}$ denote the elastic stiffness, ductility factor, yielding drift, maximum drift and equivalent secant stiffness of the supplemental system at the $i^{\text {th }}$ story, respectively; $k_{i}, \mu_{i}, \mu_{\mathrm{y}, i}$, $\mu_{\mathrm{max}, i}$ and $k_{\mathrm{eq}, i}$ denote the elastic stiffness, ductility factor, yielding drift, maximum drift and equivalent secant stiffness of the controlled structure at the $i^{\text {th }}$ story, respectively.

For convenience and safety in practical design, the damper is modelled to be elasto-perfectly plastic. Then, these mechanical parameters have the following relations [22]:

$\left\{\begin{array}{l}k_{\mathrm{deq}, i}=\frac{k_{\mathrm{d}, i} \times u_{\mathrm{dy}, i}}{u_{\mathrm{dmax}, i}} \\ \mu_{\mathrm{d}, i}=\frac{u_{\mathrm{dmax}, i}}{u_{\mathrm{dy}, i}}\end{array}\right.$

$\left\{\begin{array}{l}k_{\mathrm{a}, i}=\frac{1}{\frac{1}{k_{\mathrm{b}, i}}+\frac{1}{k_{\mathrm{d}, i}}} \\ u_{\mathrm{ay}, i}=\frac{k_{\mathrm{d}, i} \times u_{\mathrm{dy}, i}}{k_{\mathrm{a}, i}} \\ u_{\mathrm{amax}, i}=\frac{k_{\mathrm{d}, i} \times u_{\mathrm{dy}, i}}{k_{\mathrm{b}, i}}+u_{\mathrm{dmax}, i} \\ \mu_{\mathrm{a}, i}=\frac{u_{\mathrm{amax}, i}}{u_{\mathrm{ay}, i}} \\ k_{\mathrm{aeq}, i}=\frac{k_{\mathrm{a}, i}}{\mu_{\mathrm{a}, i}}\end{array}\right.$

$\left\{\begin{array}{l}k_{i}=k_{\mathrm{a}, i}+k_{\mathrm{f}, i} \\ k_{\mathrm{eq}, i}=k_{\mathrm{aeq}, i}+k_{\mathrm{f}, i} \\ u_{\mathrm{max}, i}=u_{\mathrm{amax}, i} \\ u_{\mathrm{y}, i}=u_{\mathrm{ay}, i} \\ \mu_{i}=\mu_{\mathrm{a}, i}\end{array}\right.$

In this paper, for convenience, the elastic stiffness of the brace $k_{\mathrm{b}, i}$ is valued as $\infty$, then the mechanical parameters of the supplemental system have the same values as those of the damper.

\subsection{Converting Controlled MDOF Structure to SDOF Structure and Static responses Quantities}

Referring to literature [21-23], the following hypotheses are used for converting the controlled MDOF structure to the equivalent SDOF structure:

(1) The same ductility factor $\mu_{i}$ is adopted for each story of the MDOF structure and is the same as that in the equivalent SDOF system $\mu$, i.e. $\mu_{i}=\mu,(i=1,2, \ldots, n)$.

(2) The natural period and damping ratio of the equivalent SDOF structure are equal to those of the $1^{\text {st }}$ mode of the MDOF structure, denoted as $T_{1}$ and $\zeta_{1}$ regulated, respectively.

(3) The MDOF structure has a uniform distribution of story drift angle along the height, i.e. its $1^{\text {st }}$ vibration mode is linear. Due to the conversion being based on the $1^{\text {st }}$ mode, the drift angle of the equivalent SDOF structure is equal to that of the MDOF structure.

(4) The controlled MDOF structure is assumed to be linear with an equivalent secant stiffness $k_{\text {eq }, i},(i=1,2, \ldots$, $n)$. According to Eqs. (2) and (3), $k_{\mathrm{eq}, i},(i=1,2, \ldots, n)$ is written:

$k_{\mathrm{eq}, i}=\frac{k_{\mathrm{d}, i}}{\mu}+k_{\mathrm{f}, i}$

Similarly, the equivalent secant stiffness of the SDOF structure $K_{\text {eq }}$ is written:

$K_{\text {eq }}=\frac{K_{\mathrm{d}}}{\mu}+K_{\mathrm{f}}$

where $K_{\mathrm{d}}$ is the elastic stiffness of the damper for the SDOF structure, and $K_{\mathrm{f}}$ is the elastic stiffness of the uncontrolled SDOF structure. According to literature [24], $K_{\mathrm{f}}$ is given as:

$$
\left\{\begin{array}{l}
K_{\mathrm{f}}=\frac{\left(\sum_{i=1}^{n} k_{\mathrm{f}, i} \Delta h_{i}^{2}\right) \times\left(\sum_{i=1}^{n} m_{i} h_{i}\right)^{2}}{\left(\sum_{i=1}^{n} m_{i} h_{i}^{2}\right)^{2}} \\
\Delta h_{i}=h_{i}-h_{i-1},\left(i=1,2, \ldots, n, h_{0}=0\right)
\end{array}\right.
$$

where $m_{i}$ is the lumped mass at the $i^{\text {th }}$ floor level, $h_{i}$ is the height of the $i^{\text {th }}$ floor above the base.

Based on the above hypotheses, modal analysis method gives the following static responses quantities [24]: effective modal height $H$, base shear $V_{\mathrm{b}}$, shear $V_{i}$ at the $i^{\text {th }}$ story:

$$
\begin{aligned}
& H=\frac{\sum_{i=1}^{n} m_{i} h_{i}^{2}}{\sum_{i=1}^{n} m_{i} h_{i}} \\
& V_{\mathrm{b}}=\frac{\left(\sum_{i=1}^{n} m_{i} h_{i}\right)^{2}}{\sum_{i=1}^{n} m_{i} h_{i}^{2}} \times S_{\mathrm{pa}}
\end{aligned}
$$




$$
\left\{\begin{array}{l}
V_{i}=\sum_{j=i}^{n} s_{j} \times S_{\mathrm{pa}} \\
s_{j}=\frac{\sum_{i=1}^{n} m_{i} h_{i}}{\sum_{i=1}^{n} m_{i} h_{i}^{2}} m_{j} h_{j}
\end{array}\right.
$$

where $S_{\mathrm{pa}}$ is the acceleration spectrum of the SDOF structure with $T_{1}$ and $\zeta_{1}$ regulated in the seismic code [25].

\subsection{Determining Distribution of Elastic Stiffness of Damper on MDOF Structure}

Story drift is a quotient of story shear and story stiffness. Considering the MDOF structure and the SDOF structure have the same story drift angle, the following equation is written:

$$
\frac{\Delta h_{i}}{H}=\frac{V_{i} \times K_{\mathrm{eq}}}{V_{\mathrm{b}} \times k_{\mathrm{eq}, i}}
$$

Substituting Eqs. (5) and (6) in Eq. (11), $k_{\mathrm{d}, i}$ is written:

$$
k_{\mathrm{d}, i}=\frac{H \times V_{i} \times K_{\mathrm{f}} \times\left(\mu+\frac{K_{\mathrm{d}}}{K_{\mathrm{f}}}\right)}{\Delta h_{i} \times V_{\mathrm{b}}}-\mu \times k_{\mathrm{f}, i}
$$

If the calculated value of $k_{\mathrm{d}, i}$ is less than $0, k_{\mathrm{d}, i}$ is set to be 0 . In fact, Eq. (11) is consistent with that in literature [22].

\subsection{Design Program}

In this paper, seismic control design of structures has the following targets: (1) the story drift angle of the controlled structure does not exceed the elastic limit in order to assure the structure being damage-free state; (2) the controlled structure appears a uniform distribution of story drift angle along the height, whether it is regular in elevation or not. In addition, the procedure is universal for any code-consistent structure.

Fig. 2 shows the flowchart of the design procedure. The steps are in the following:

Step 1: The story drift angle limit $\theta$ is first determined. If the story drift angle of the uncontrolled structure subjected to earthquake exceeds the limit $\theta$, seismic control design is carried on.

Step 2: The iterations and the ductility factor $\mu$ are assigned a reasonable value, respectively.

Step 3: The stiffness ratio $K_{\mathrm{d}} / K_{\mathrm{f}}$ is assigned a reasonable value, and the elastic stiffness of damper $k_{\mathrm{d}, i},(i$ $=1,2, \ldots, n)$ are calculated from Eqs. (4) to (11).

Step 4: The yielding drift of damper $\mu_{\mathrm{dy}, i},(i=1,2, \ldots$, $n$ ) is assigned initial value as $\mu_{\mathrm{dy}, i}=\theta \times \Delta h_{i} / \mu$.

Step 5: Time history analysis is performed on the controlled structure excited by earthquake. Taken the $i^{\text {th }}$ for example, the maximum story drift angle $\theta_{i}$ is got, so the ductility factor $\mu_{i}$ is derived from $\mu_{i}=\theta_{i} \times \Delta h_{i} / \mu_{\mathrm{dy}, i}$. Here, the ductility factor of the damper is equal to that of the structure.
Step 6: If within the iteration, $\theta_{i}>\theta$ or $\left|\mu_{i}-\mu\right|>\varepsilon,(i=$ $1,2, \ldots, n),(\varepsilon$ is a very small value $), \mu_{\mathrm{dy}, i}$ is renewed as $\mu_{\mathrm{dy}, i}$ $=\theta_{i} \times \Delta h_{i} / \mu$, and Steps 5 and 6 are repeated until $\mu_{i}$ and $\theta_{i}$ converge. Else, if $\mu_{i}$ and $\theta_{i}$ diverge within the iteration, $K_{\mathrm{d}} / K_{\mathrm{f}}$ should be updated, and Steps 3 to 6 should be repeated until convergence is attained. This step also ensures that the final story ductility factor $\mu_{i}$ is approximately equal to the preset value.

In this study, detailed configuration design of the damper is not involved.

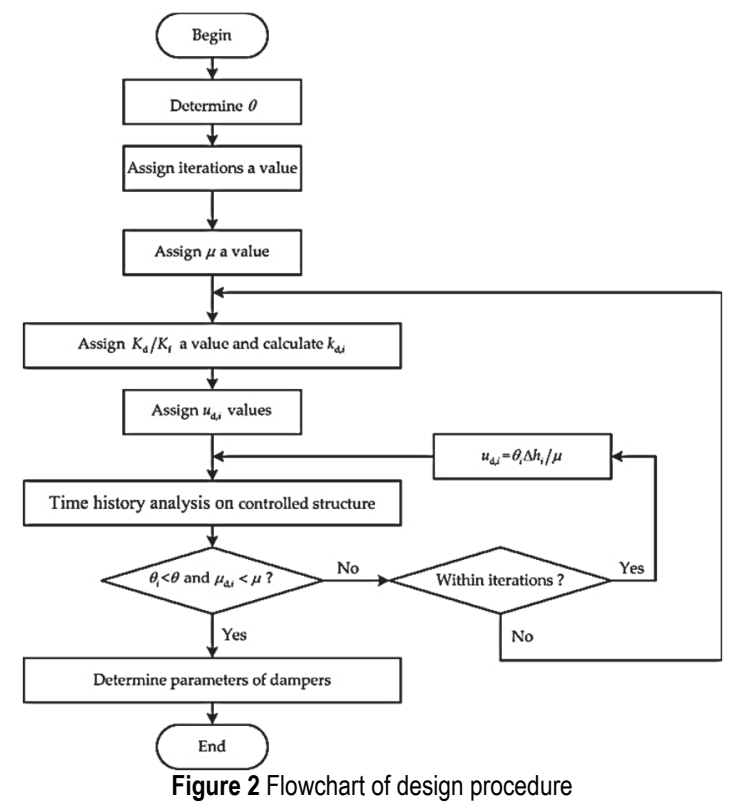

3 NUMERICAL VERIFICATION

The proposed procedure is used to design the example structures, and its correctness is examined through time history analysis method.

\subsection{Numerical Example Description 3.1.1 Structural Models}

A total of three shear type moment resisting steel frame models, which are numbered 1 to 3 , are considered. The three models are all 10 stories high, and have the same story height and lumped mass on each story. Model 1 uses the frame in [22], which is designed with a uniform distribution of elastic stiffness along the height. Models 2 and 3 contain the soft stories in upper stories and lower stories, respectively. The fundamental periods for Models 1 to 3 are $1.99 \mathrm{~s}, 1.83 \mathrm{~s}$ and $1.80 \mathrm{~s}$, respectively, and the damping ratios are all 0.04 . The structural parameters of the 3 models are listed in Tab. 1 .

Table 1 Parameters of 3 structural models

\begin{tabular}{|c|c|c|c|c|c|}
\hline $\begin{array}{c}\text { Story } \\
\text { No. }\end{array}$ & \multirow{2}{*}{$h_{i} / \mathrm{cm}$} & $m_{i} / \mathrm{kg}$ & Model 1 & Model 2 & Model 3 \\
\hline 1 & 600 & 685910 & 2799.60 & 4114.74 & 3023.57 \\
\hline 2 & 1000 & 668020 & 3835.50 & 5637.26 & 4142.34 \\
\hline 3 & 1400 & 666410 & 3830.20 & 5629.47 & 4136.62 \\
\hline 4 & 1800 & 662260 & 3282.60 & 4824.63 & 3545.21 \\
\hline 5 & 2200 & 656670 & 3061.60 & 4499.82 & 4776.10 \\
\hline 6 & 2600 & 653930 & 2918.90 & 3821.38 & 4553.48 \\
\hline 7 & 3000 & 647010 & 2447.90 & 1762.49 & 3818.72 \\
\hline 8 & 3400 & 643090 & 2202.50 & 1585.80 & 3435.90 \\
\hline 9 & 3800 & 636460 & 1801.10 & 1296.79 & 2809.72 \\
\hline 10 & 4200 & 857900 & 1585.50 & 936.00 & 2473.38 \\
\hline
\end{tabular}




\subsubsection{Earthquake Ground Motions}

Four artificial ground motions that are compatible with the design spectrum as regulated in the seismic code [25] are considered. The characteristic period of the design spectrum is $0.4 \mathrm{~s}$.

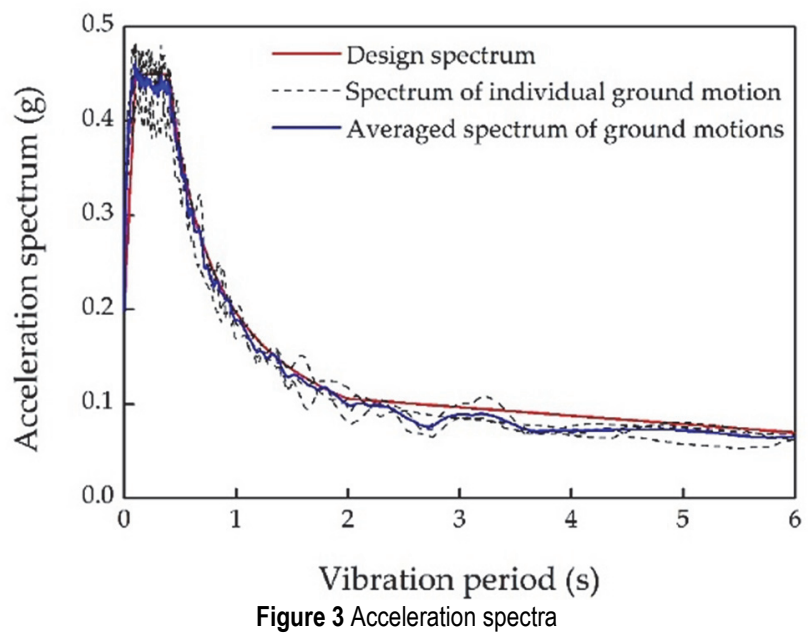

Fig. 3 plots the acceleration spectra of 4 ground motions accompanied by the design spectrum. In this study, the peak ground accelerations (PGAs) are scaled to $0.3 \mathrm{~g}$ for Models 1 and 3 and $0.2 \mathrm{~g}$ for Model 2 .

\subsection{Damper Design}

Dampers are placed on the stories of the structure with the chevron braces, as shown in Fig. 1a. The stiffness of the braces is all assumed as $\infty$.

\subsubsection{Mechanical Model of Damper}

Elasto-perfectly plastic hysteresis of the damper is represented by the Bouc-Wen model in the following form [26]:

$$
\left\{\begin{array}{l}
f_{\mathrm{d}}(t)=\alpha k_{\mathrm{d}} u_{\mathrm{d}}(t)+(1-\alpha) k_{\mathrm{d}} u_{\mathrm{dy}} z(t) \\
\dot{z}(t)=\frac{1}{u_{\mathrm{dy}}}\left[\begin{array}{l}
A \dot{u}_{\mathrm{d}}(t)-\beta\left|\dot{u}_{\mathrm{d}}(t)\right||z(t)|^{\eta-1} z(t)- \\
-\gamma \dot{u}_{\mathrm{d}}(t)|z(t)|^{\eta}
\end{array}\right]
\end{array}\right.
$$

where $f_{\mathrm{d}}(t)$ and $u_{\mathrm{d}}(t)$ are the force and drift of the damper, respectively, $k_{\mathrm{d}}$ is the elastic stiffness, $u_{\mathrm{dy}}$ is the yielding drift, $\alpha$ is the post- to pre-yielding stiffness ratio, $A, \beta, \gamma$ and $\eta$ are non-dimensional parameters controlling the shape and the size of the hysteresis loop, and $\dot{u}_{\mathrm{d}}(t)$ and $\dot{z}(t)$ denote the time derivative.

\subsubsection{Determining Mechanical Parameters of Dampers}

The mechanical parameters of the damper, such as $\alpha$, $A, \beta, \gamma$ and $\eta$ are attained by trials: $\alpha=0, A=1, \beta=0.9, \gamma=$ 0.1 and $\eta=500$. Other parameters, e.g. $k_{\mathrm{d}, i}, u_{\mathrm{dy}, i}$ and $\mu_{i},(i=$ $1,2, \ldots, n)$ are determined by iterative calculations in the design procedure. In this procedure, some parameters are determined in the following: $\theta$ is valued as $1 / 250$, which is consistent with the statement in the seismic code [25]; the ductility factor $\mu$ and the iterations are set to 4 and 15 , respectively. The same value is assigned to $K_{\mathrm{d}} / K_{\mathrm{f}}$ for the 4 ground motions to avoid generating discrete solutions. Although $u_{\mathrm{dy}, i}$ and $\mu_{\mathrm{d}, i}$ are calculated under individual ground motion, their averages over the 4 ground motions are adopted to ensure the solutions being more accurately approximated. Tab. 2 lists the solutions of the three models.

Table 2 Parameters of dampers.

\begin{tabular}{|c|c|c|c|c|c|c|c|c|c|}
\hline \multirow{2}{*}{ Story No. } & \multicolumn{3}{|c|}{ Model 1} & \multicolumn{3}{c|}{ Model 2 } & \multicolumn{2}{c|}{ Model 3} \\
\cline { 2 - 10 } & $k_{\mathrm{d}, i} / \mathrm{kN} / \mathrm{cm}$ & $u_{\mathrm{dy}, i} / \mathrm{cm}$ & $\mu_{i}$ & $k_{\mathrm{d}, i} / \mathrm{kN} / \mathrm{cm}$ & $u_{\mathrm{dy}, i} / \mathrm{cm}$ & $\mu_{i}$ & $k_{\mathrm{d}, i} / \mathrm{kN} / \mathrm{cm}$ & $u_{\mathrm{dy}, i} / \mathrm{cm}$ & $\mu_{i}$ \\
\hline 1 & 5181.61 & 0.44 & 4.00 & 0.00 & 0.40 & 4.05 & 5165.79 & 0.51 & 4.01 \\
\hline 2 & 8615.14 & 0.28 & 4.00 & 0.00 & 0.28 & 4.03 & 8674.93 & 0.31 & 4.04 \\
\hline 3 & 7641.52 & 0.27 & 4.01 & 0.00 & 0.26 & 4.03 & 7649.56 & 0.32 & 3.99 \\
\hline 4 & 8442.53 & 0.27 & 3.97 & 440.61 & 0.27 & 4.05 & 8551.15 & 0.32 & 4.09 \\
\hline 5 & 7551.30 & 0.26 & 4.03 & 115.55 & 0.27 & 4.04 & 1756.99 & 0.32 & 3.95 \\
\hline 6 & 5970.69 & 0.27 & 4.00 & 860.78 & 0.27 & 4.04 & 380.44 & 0.32 & 3.98 \\
\hline 7 & 5322.72 & 0.28 & 4.02 & 6779.59 & 0.28 & 3.92 & 651.47 & 0.34 & 3.93 \\
\hline 8 & 3413.73 & 0.30 & 3.93 & 4841.46 & 0.28 & 3.94 & 0.00 & 0.35 & 3.99 \\
\hline 9 & 1763.18 & 0.34 & 4.01 & 3018.13 & 0.30 & 3.98 & 0.00 & 0.38 & 3.97 \\
\hline 10 & 0.00 & 0.36 & 4.00 & 1165.75 & 0.34 & 4.05 & 0.00 \\
\hline
\end{tabular}

\subsection{Numerical Results and Analysis}

Time history analyses on the three models with/without the dampers subjected to the 4 ground motions are performed. Figs. 4 to 6 show the story drift angles of the three models, including the response for the individual ground motion, the averaged response over the 4 ground motions and the response limit. Some phenomena can be seen:

(1) For the uncontrolled structures, Model 1 develops a uniform distribution of story drift angle along the height except that the top story has a relatively small drift angle.
Models 2 and 3 develop considerable story drift angles in the upper 4 stories and the lower 4 stories, respectively, as expected. The peak story drift angles of the 3 models all exceed $1 / 250$.

(2) For all three controlled models, although the story drift angles from some individual ground motion exceed the limit of $1 / 250$, the story drift angles are all effectively reduced below $1 / 250$ on average. What is more, an approximately uniform distribution of story drift angle along the height is achieved for the structure, whether it is regular in elevation or not. Comparisons show that the proposed program is effective. 


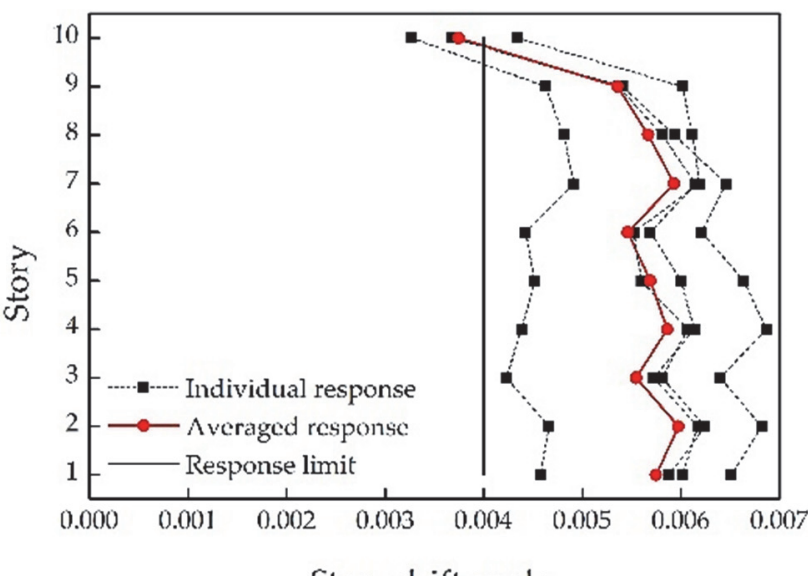

Story drift angle

(a)

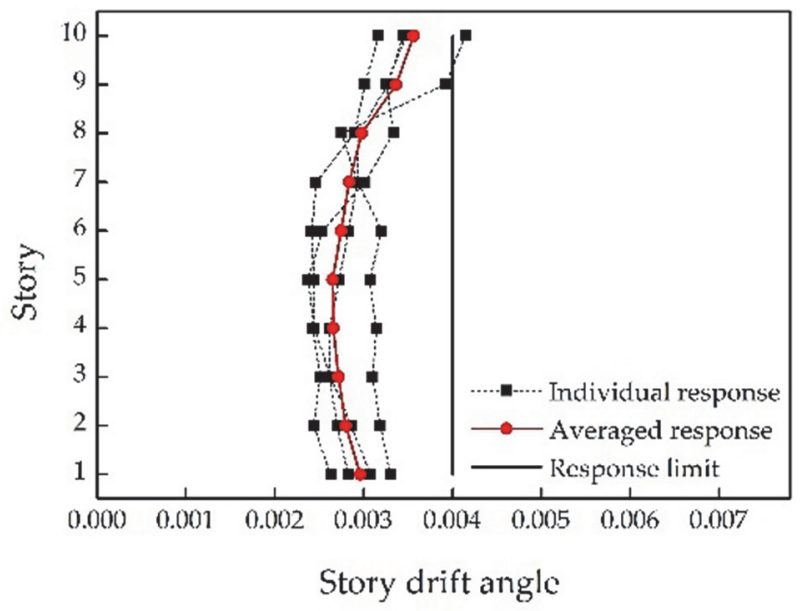

(b)

Figure 4 Story drift angles of Model 1. (a) Uncontrolled structure; (b) Controlled structure

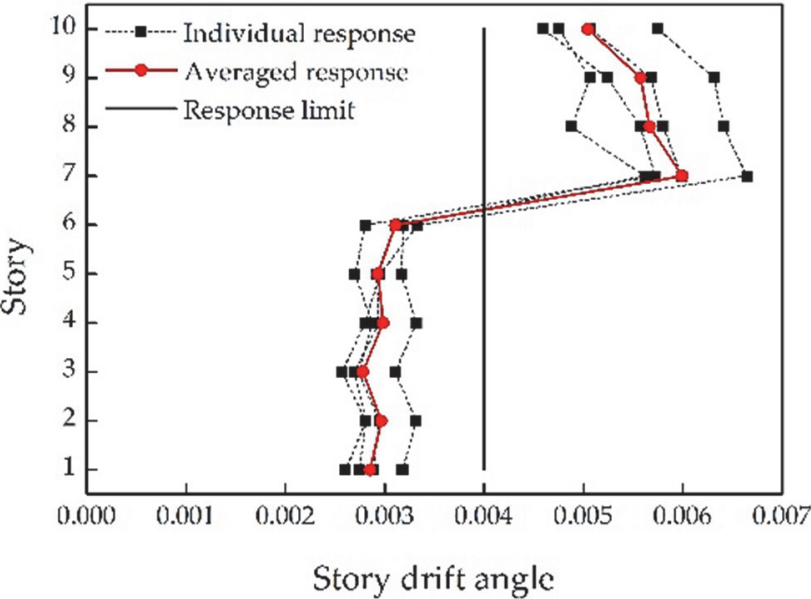

(a)

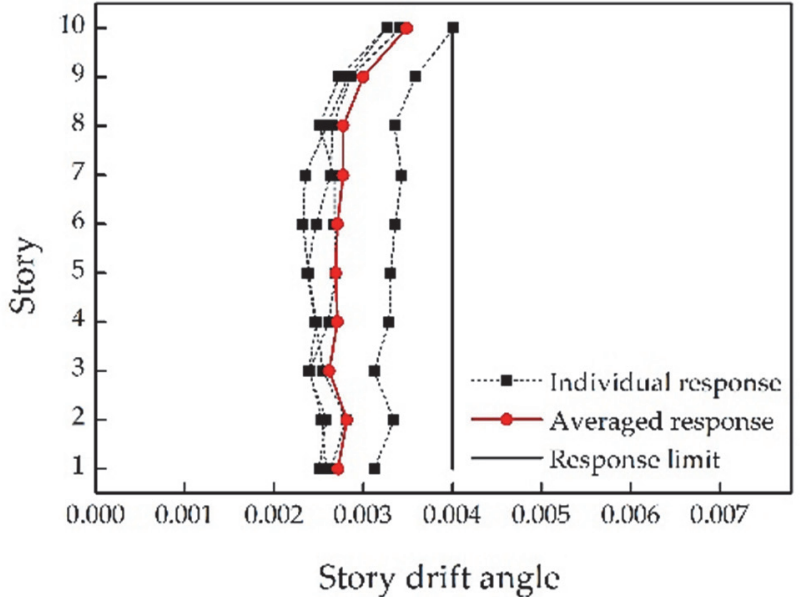

(b)

Figure 5 Story drift angles of Model 2. (a) Uncontrolled structure; (b) Controlled structure

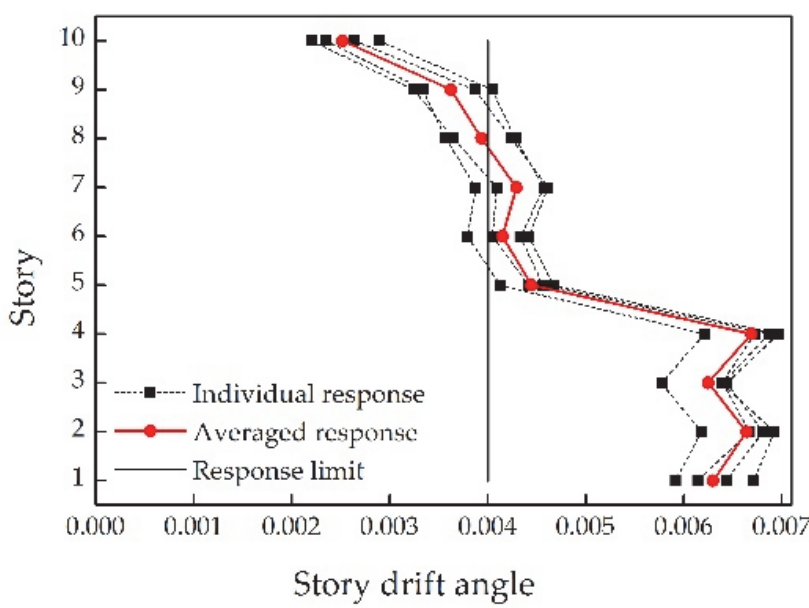

(a)

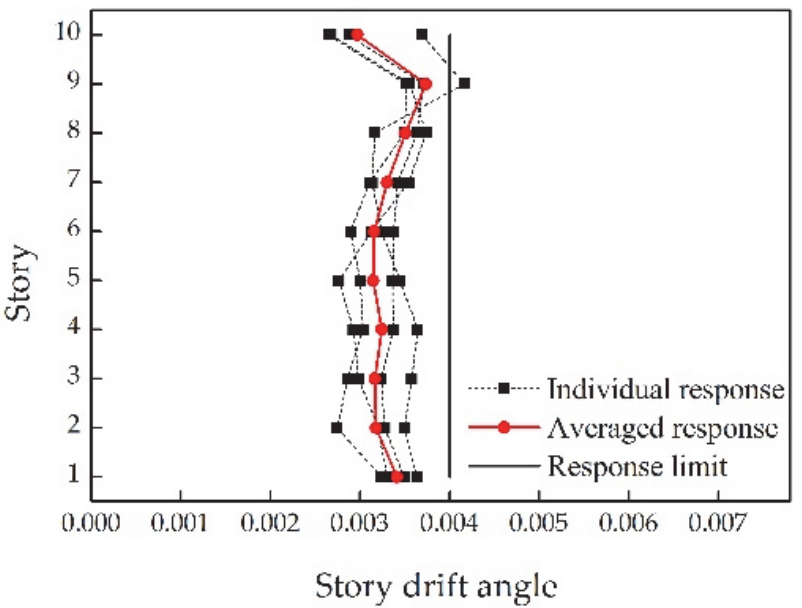

(b)

Figure 6 Story drift angles of Model 3. (a) Uncontrolled structure; (b) Controlled structure.

Comparing Tab. 2 with Figs. 4 to 6, it is shown that the distribution of damper's elastic stiffness along the height seems to match the story drift angle distribution of the uncontrolled structure. Model 1 has dampers on all the stories except the top level. Because the upper 4 stories are soft in Model 2, the damper's elastic stiffness on the upper 4 stories are much larger than those on other stories. Similarly for Model 3, the dampers on the lower 4 stories have evidently increased elastic stiffness relative to other stories, attributed to the lower soft stories.

Taking Model 1 for example, Fig. 7 plots the hysteretic curves of the dampers on each story. As expected, the dampers appear elasto-perfectly plastic mechanical properties with more energy dissipation, which indirectly validates the correctness of the calculations and the effectiveness of the design procedure. 


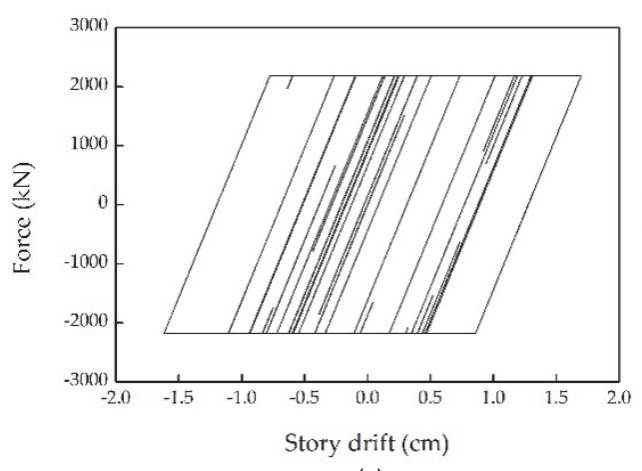

(a)

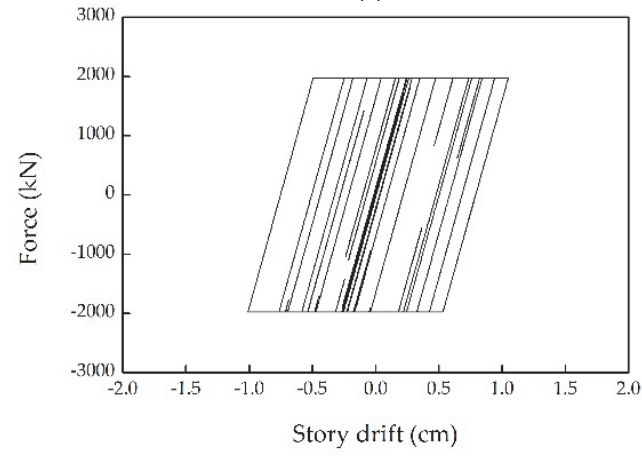

(c)

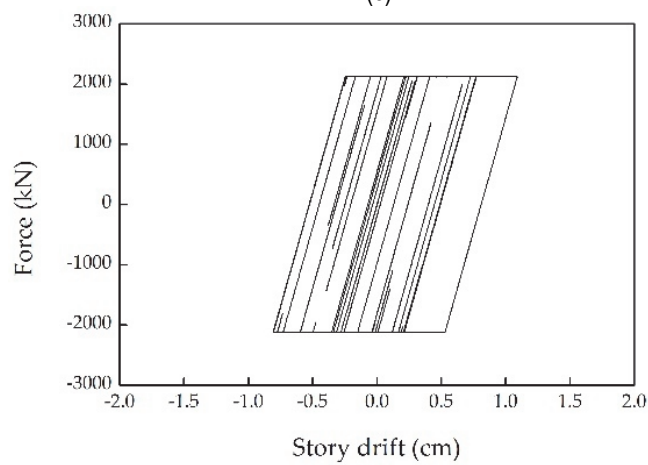

(e)

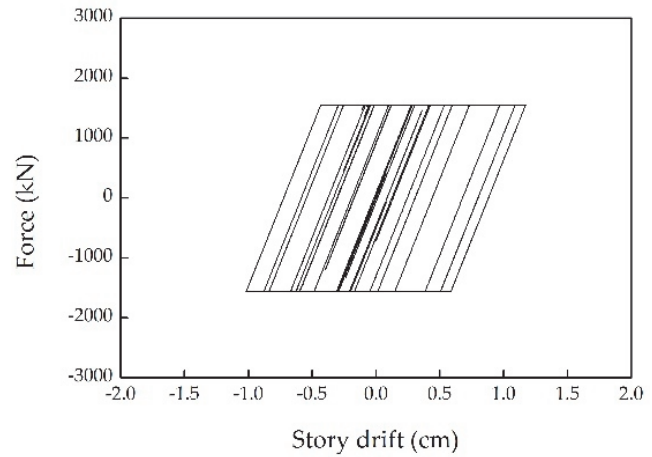

(g)

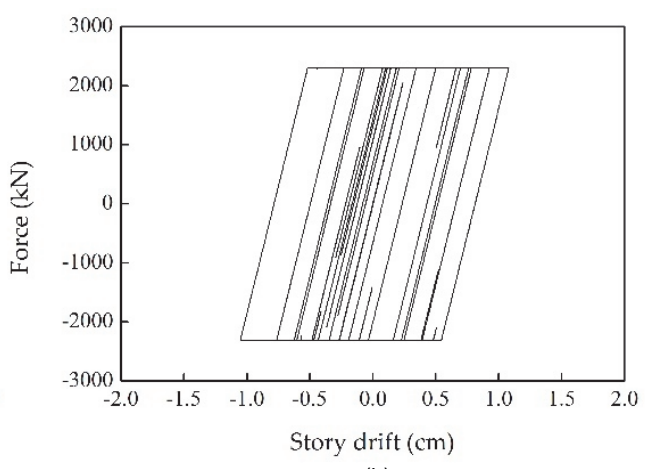

(b)

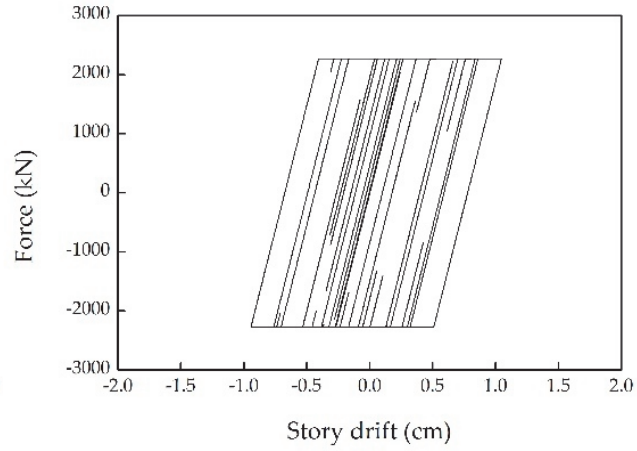

(d)

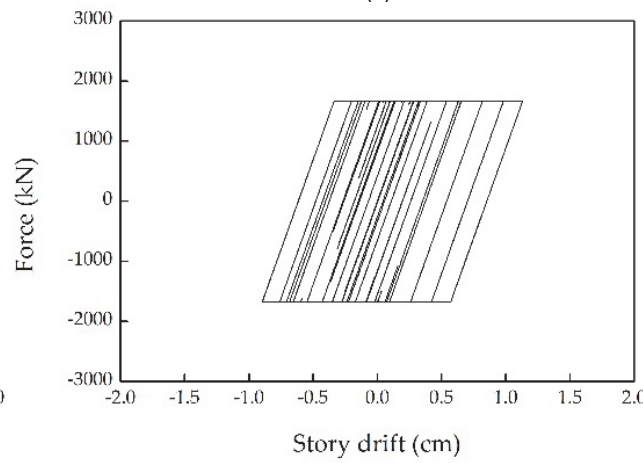

(f)

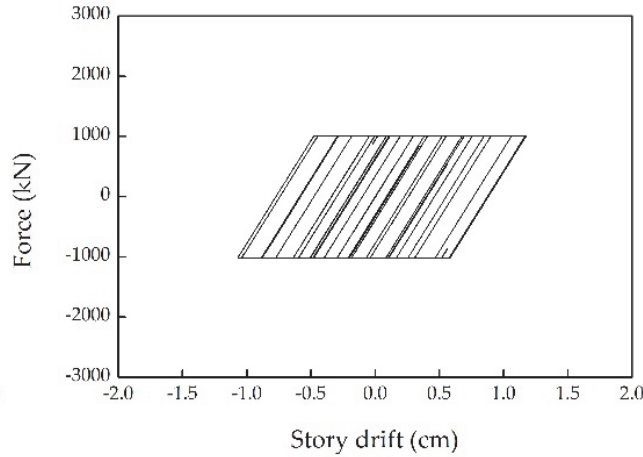

(h)

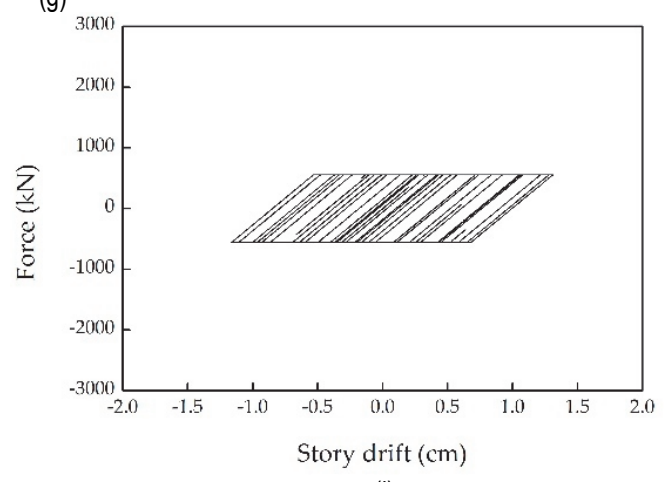

(i)

Figure 7 Hysteretic curves of dampers. (a) The $1^{\text {st }}$ story; (b) The $2^{\text {nd }}$ story; (c) The $3^{\text {rd }}$ story; (d) The $4^{\text {th }}$ story; (e) The $5^{\text {th }}$ story; (f) The $6^{\text {th }}$ story; (g) The $7^{\text {th }}$ story; (h) The $8^{\text {th }}$ story; (i) The $9^{\text {th }}$ story 


\section{CONCLUSIONS}

In this study, a new methodology for seismic control design of MDOF structures is put forward. The structure is a shear-type building frame, and the hysteretic damper is modeled to be elasto-perfectly plastic. Referring to literature [22], the mechanical parameters of the damper, the supplemental system (damper + brace) and the controlled structure are defined. Based on modal analysis method, the controlled MDOF structure is converted to the equivalent SDOF structure, then the elastic stiffness of the damper $k_{\mathrm{d}, i}$ is formulated, which is consistent with that in literature [22]. A procedure is compiled to achieve the mechanical parameters of the damper on each story of the MDOF structure, such as the elastic stiffness, the yielding drift and the ductility factor. Finally, the procedure is used for seismic control design of three example structures, among which one is regular in elevation and others have soft stories in upper or lower stories. Time history analyses show that not only the story drift angles of the controlled structures are effectively reduced, but also the controlled structures appear an approximately uniform distribution of story drift angle along the height, whether it is regular in elevation or not. In addition, the procedure is universal for any code-consistent structure.

The proposed methodology is feasible for practical application. However, due to $\mu$ and $K_{\mathrm{d}} / K_{\mathrm{f}}$ being valued arbitrarily, the solutions may be not optimal. Future research will be conducted to search the optimum mechanical parameters of dampers in order to assure the safety of structures at a small cost.

\section{Acknowledgements}

This research was funded by the National Natural Science Foundation of China (grant number 51878240).

\section{REFERENCES}

[1] Tsai, C. S., Lin, Y. C., Chen, W. S., \& Su H. C. (2009). Mathematical modeling and full-scale shaking table tests for multi-curve buckling restrained braces. Earthquake Engineering and Engineering Vibration, 8(3), 359-371. https://doi.org/10.1007/s11803-009-9004-9

[2] Sorace, S., Terenzi, G., \& Fadi, F. (2012). Shaking table and numerical seismic performance evaluation of a fluid viscousdissipative bracing system. Earthquake Spectra, 28(4), 1619-1642. https://doi.org/10.1193/1.4000083

[3] Benavent-Climent, A., Morillas L., \& Escolano-Margarit D. (2014). Seismic performance and damage evaluation of a reinforced concrete frame with hysteretic dampers through shake-table tests. Earthquake Engineering and Structural Dynamics, 43(15), 2399-2417. https://doi.org/10.1007/s40069-013-0046-z

[4] Eatherton, M. R., Fahnestock, L. A., \& Miller, D. J. (2014). Computational study of self-centering buckling-restrained braced frameseismic performance. Earthquake Engineering and Structural Dynamics, 43(13), 1897-1914. https://doi.org/10.1002/eqe.2428

[5] Guerrero, H., Escobar, J. A., \& Teran-Gilmore, A. (2018). Experimental damping on frame structures equipped with buckling-restrained braces (BRBs) working within their linear-elastic response. Soil Dynamics and Earthquake Engineering, 106, 196-203.

https://doi.org/10.1016/j.soildyn.2017.12.028
[6] Mohsenian, V. \& Mortezaei, A. (2019). A new energyabsorbing system for seismic retrofitting of frame structures with slender braces. Bulletin of Earthquake Engineering, 17(5), 2715-2739. https://doi.org/10.1007/s10518-018-00543-7

[7] Naghavi, M., Rahnavard, R., Thomas, R.J., \& Malekinejad, M. (2019). Numerical evaluation of the hysteretic behavior of concentrically braced frames and buckling restrained brace frame systems. Journal of Building Engineering, 22, 415-428.https://doi.org/10.1016/j.jobe.2018.12.023

[8] Lin, Y. Y., Tsai, M. H., Hwang, J. S., \& Chang K. C. (2019). Direct displacement-based design for building with passive energy dissipation systems. Engineering Structures, 25(1), 25-37. https://doi.org/10.1016/s0141-0296(02)00099-8

[9] Ataei, H. \& Anaraki, K. K. (2018). A proposed structural design method considering fluid viscous damper degradations. The Structural Design of Tall and Special Buildings, 27(3), e1512. https://doi.org/10.1002/tal.1512

[10] Sun, T., Kurama, Y. C., \& Ou, J. P. (2018). Practical displacement-based seismic design approach for PWF structures with supplemental yielding dissipators. Engineering Structures, 172, 538-553. https://doi.org/10.1016/j.engstruct.2018.05.120

[11] Kim, J., Choi, H., \& Chung, L. (2004). Energy-based seismic design of structures with buckling-restrained braces. Steel and Composite Structures, 4(6), 437-452. https://doi.org/10.12989/scs.2004.4.6.437

[12] Khampanit, A., Leelataviwat, S., Kochanin, J., \& Warnitchai, P. (2014). Energy-based seismic strengthening design of non-ductile reinforced concrete frames using bucklingrestrained braces. Engineering Structures, 81, 110-122. https://doi.org/10.1016/j.engstruct.2014.09.033

[13] Benavent-Climent, A. \& Mota-Páez, S. (2017). Earthquake retrofitting of $\mathrm{R} / \mathrm{C}$ frames with soft first story using hysteretic dampers: energy-based design method and evaluation. Engineering Structures, 137, 19-32. https://doi.org/10.1016/j.engstruct.2017.01.053

[14] Serror, M. H., Diab, R. A., \& Mourad, S. A. (2014). Seismic force reduction factor for steel moment resisting frames with supplemental viscous dampers. Earthquakes and Structures, 7(6), 1171-1186. https://doi.org/10.12989/eas.2014.7.6.1171

[15] Kalapodis, N. A., Papagiannopoulos, G. A., \& Beskos, D. E. (2018). Modal strength reduction factors for seismic design of plane steel braced frames. Journal of Constructional Steel Research, 147, 549-563. https://doi.org/10.1016/j.jcsr.2018.05.004

[16] Zhang, S. H., Liang, X. W., \& Deng, M. K. (2006). Study on the capacity-spectrum seismic design method for buildings equipped with passive energy dissipation systems. Tumu Gongcheng Xuebao, 39(7), 26-32. https://doi.org/10.1016/S1872-2032(06)60021-8

[17] Bantilas, K. E., Kavvadias, I. E., \& Vasiliadis, L. K. (2017). Capacity spectrum method based on inelastic spectra for high viscous damped buildings. Earthquakes and Structures, 13(4), 337-351. https://doi.org/10.12989/eas.2018.13.4.337

[18] Terazawaa, Y. \& Takeuchi, T. (2018). Generalized response spectrum analysis for structures with dampers. Earthquake Spectra, 34(3), 1459-1479. https://doi.org/10.1193/092217EQS188M

[19] De la Llera, J. C., Munoz, J. P., \& Besa, J. J. (2019). A design procedure for buildings equipped with energy dissipation devices using nonclassical damping and iso-performance curves. Earthquake Engineering and Structural Dynamics, 48(2), 210-231. https://doi.org/10.1002/eqe.3132

[20] Taiyari, F., Mazzolani, F. M., \& Bagheri, S. (2019). Damage-based optimal design of friction dampers in multistory chevron braced steel frames. Soil Dynamics and Earthquake Engineering, 119, 11-20. https://doi.org/10.1016/j.soildyn.2019.01.004 
[21] Kasai, K., Fu, Y., \& Watanabe, A. (1998). Passive control systems for seismic damage mitigation. Journal of Structural Engineering, 124(3), 501-512. https://doi.org/10.1061/(ASCE)0733-9445(1998)124:5(501)

[22] Japan Society of Seismic Isolation (JSSI). (2018).Design and Construction Manual for Passive Controlled Structures, 2nd ed.. China Architecture \& Building Press.

[23] Pu, W. C., Liu, C. C., Zhang, H., \& Kasai, K. (2016). Seismic control design for slip hysteretic timber structures based on tuning the equivalent stiffness. Engineering Structures, 128, 199-214. https://doi.org/10.1016/j.engstruct.2016.09.041

[24] Chopra, A. K. (2017). Dynamics of Structures: Theory and Applications to Earthquake Engineering, 3rd ed.. Pearson Prentice Hall: Upper Saddle River, NJ, USA.

[25] National Standard of the People's Republic of China. (2016). Code for Seismic Design of Building (GB 50011-2010). China Building Industry Press.

[26] Ikhouane, F., Hurtado, J. E., \& Rodellarb, J. (2007). Variation of the hysteresis loop with the Bouc-Wen model parameters. Nonlinear Dynamics, 48(4), 361-380.

https://doi.org/10.1007/s11071-006-9091-3

\section{Contact information:}

Wenjie REN, PhD, Professor

(Corresponding author)

School of Civil and Transportation Engineering,

Hebei University of Technology,

5340 Xiping Road, Beichen District, Tianjin, China

E-mail: rwjwlq@126.com

Fengmei PI, PhD Candidate, Lecturer

1) School of Civil and Transportation Engineering,

Hebei University of Technology,

5340 Xiping Road, Beichen District, Tianjin, China

2) Institute of Architecture Civil Engineering,

Langfang Normal University,

100 Aimin West Road, Langfang City, Hebei Province, China

E-mail: pyhwyb@126.com

Bowen CHEN, PhD Candidate, Lecturer

School of Civil and Transportation Engineering,

Hebei University of Technology,

5340 Xiping Road, Beichen District, Tianjin, China

E-mail: bowen_db@126.com 